\title{
Effects of Sputter Order and Oxide Layer on Amorphous Formation of Zr-Ni Thin Film System
}

\author{
Masahiro Kitada and Fumiyoshi Kirino \\ Graduate School of Fine Arts, Tokyo National University of Fine Arts and Music, Tokyo 110-8714, Japan
}

Effects of the sputtering order and the presence of an oxide layer on an amorphous metal layer formation of zirconium-nickel bilayer thin films annealed at $623 \mathrm{~K}\left(350^{\circ} \mathrm{C}\right)$ have been investigated. Nickel species are found to diffuse preferentially from the nickel layer into the zirconium layer in $\mathrm{Zr} / \mathrm{Ni}$ bilayer thin film. From this diffusion, the amorphous phase and voids are formed. However, by the change of the sputtering order and with the formation of a $\mathrm{Zr}$ oxide layer, the amorphous and voids are not formed. This indicates that nickel species migrate into the amorphous layer by means of vacancies. Vacancies are supplied from the zirconium-free surface.

(Received October 1, 2004; Accepted December 24, 2004)

Keywords: zirconium-nickel system, thin film, diffusion, amorphous, oxide layer, void

\section{Introduction}

Amorphous phases are formed by various means, for example, rapid quenching, ${ }^{1)}$ irradiation, ${ }^{2}$ ) co-sputtering, ${ }^{3)}$ interdiffusion $^{4)}$ and others. ${ }^{5-7)}$ On the other hand, recently a bulk amorphous alloy has been extensively developed as a metallic glass. ${ }^{8)}$ Amorphous phase formation in multilayer thin films by solid-state diffusion is very important in thin film device application as it affects various characteristics of devices, for example, their reliability and the device yield. ${ }^{9)}$ The amorphous phase formation can be observed by a transmission electron microscope. ${ }^{10)}$

In the zirconium-permalloy bilayer thin film system, the amorphous phase is formed by interdiffusion between the films and Kirkendall voids are produced by preferential diffusion of Ni species. ${ }^{11)}$ To produce the void, it is necessary that many vacancies migrate to the permalloy thin film side from the $\mathrm{Zr}$ thin film side. However, the supply source of vacancies has not been confirmed. Changing the position of the bilayer thin film, the diffusion path, the formation of diffusion barrier, and other parameters of the diffusion system are effective strategies that can be employed to clarify the vacancy source or diffusion mechanism. Since the diffusion behavior of $\mathrm{Zr}$-permalloy system is very complex, a $\mathrm{Zr}-\mathrm{Ni}$ system was chosen as a simpler case. ${ }^{12-14)}$

In this paper the effects of the sputtering order and of the presence of an oxide layer on the $\mathrm{Zr}-\mathrm{Ni}$ thin film system are described.

\section{Experimental Details}

Zr-Ni thin films were prepared using a conventional rfsputtering system. The ultimate vacuum before sputtering was $10^{-5} \mathrm{~Pa}$. The target material purities were 99.99 mass\%. The substrate was Corning No. 7059 glass. The substrate was heated to $473 \mathrm{~K}\left(200^{\circ} \mathrm{C}\right)$ to sputter the underlayer and maintained under $323 \mathrm{~K}\left(50^{\circ} \mathrm{C}\right)$ during the upper layer sputtering to avoid a reaction between the films. The film thicknesses were approximately $50 \mathrm{~nm}$ for $\mathrm{Zr}$ and $25 \mathrm{~nm}$ for $\mathrm{Ni}$. If necessary, oxide layers were formed on $\mathrm{Ni}$ and $\mathrm{Zr}$ by introducing six-nine purity gas into the vaccum chamber. $\mathrm{Ni}$ and $\mathrm{Zr}$ oxide layers were naturally grown as six-nine purity oxygen gas was introduced into a vacuum chamber. The oxidation time was $3600 \mathrm{~s}(1 \mathrm{~h})$. After sputtering, the films were annealed at $623 \mathrm{~K}\left(350^{\circ} \mathrm{C}\right)$ for 3600 to $7200 \mathrm{~s}(1$ to $2 \mathrm{~h})$ in the sputtering chamber in a vacuum of $10^{-5} \mathrm{~Pa}$.

The cross sectional microstructure of the specimens was observed by means of transmission electron microscopy. The specimens were finally thinned by ion etching.

Depth-composition profiles were obtained by AES. The depth for AES measurement was obtained from the sputtering rate. The composition of the mixed layer was determined by EDX attached to the transmission electron microscope.

\section{Results and Discussion}

\section{1 $\mathrm{Zr} / \mathrm{Ni}$ thin film}

Cross-sectional transmission electron micrograph of $\mathrm{Zr}$ / $\mathrm{Ni}(/$ glass substrate $)$ system after annealing at $623 \mathrm{~K}\left(350^{\circ} \mathrm{C}\right)$ for $3600 \mathrm{~s}(1 \mathrm{~h})$ is shown in Fig. 1. By the reaction between the films, four regions were observed in the cross-section. The top region is approximately $18 \mathrm{~nm}$ in thickness and is unreacted $\mathrm{Zr}$ and shows crystallographic contrast. No Ni

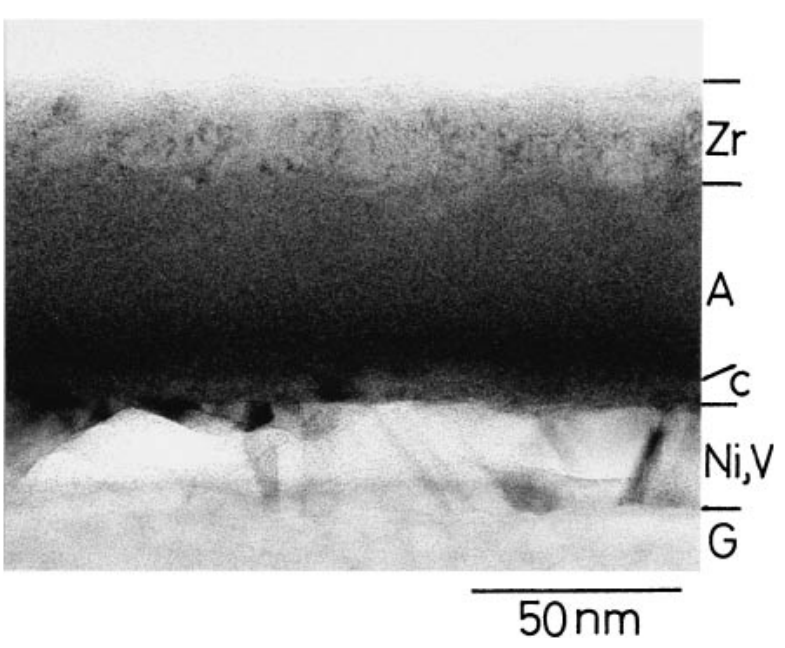

Fig. 1 Cross sectional transmission electron micrograph of $\mathrm{Zr} / \mathrm{Ni}$ bilayer thin film annealed at $623 \mathrm{~K}\left(350^{\circ} \mathrm{C}\right)$ for $3600 \mathrm{~s}(1 \mathrm{~h})$. A, C, V and $\mathrm{G}$ indicate amorphous, crystal, void and glass substrate, respectively. 


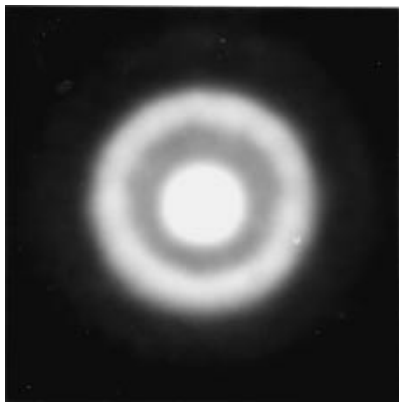

Fig. 2 Electron diffraction pattern of the amorphous region shown in Fig. 1.

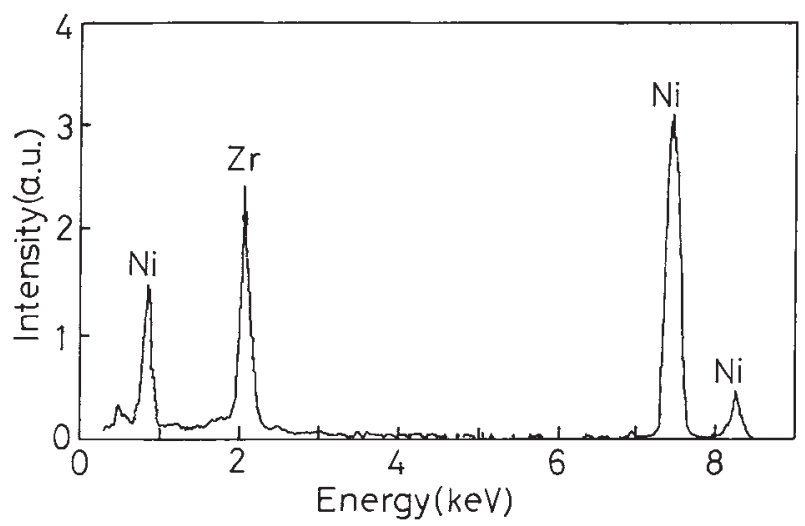

Fig. 3 Typical EDX spectrum of the mixing layer shown in Fig. 1.

species were detected in this layer by EDX. Since the electron diffraction pattern obtained from the second region is a halo, as shown in Fig. 2, the region is amorphous. Its thickness was approximately twice that of the unreacted $\mathrm{Zr}$ layer. The third region between the amorphous region and the Ni layer was Ni rich phase (about Ni-10 mol\% Zr, as obtained by EDX) and shows very small crystal size of 5 to $6 \mathrm{~nm}$ in diameter. The fourth $15 \mathrm{~nm}$ thick region is what remains from the $25 \mathrm{~nm}$ that was deposited. This region contains several voids. The typical EDX spectrum of the second amorphous region is shown in Fig. 3. From the spectrum it is clear that the amorphous region is a mixture of $\mathrm{Ni}$ and $\mathrm{Zr}$. It is thought that the voids were due to a preferential diffusion of $\mathrm{Ni}$ species towards the mixing layer by a vacancy-like mechanism. Inversely, vacancies migrated to the Ni layer from the $\mathrm{Zr}$ layer. In all respects, the Kirkendall diffusion occurred in the thin film system.

Depth-composition profiles for $\mathrm{Zr} / \mathrm{Ni}$ film annealed at $623 \mathrm{~K}\left(350^{\circ} \mathrm{C}\right)$ for $3600 \mathrm{~s}(1 \mathrm{~h})$ are shown in Fig. 4. The relative concentration of $\mathrm{Zr}$ decreases monotonically with increasing depth. However, the curve for $\mathrm{Ni}$ was not monotone and shows a peak near the third region as mentioned above. Then the concentration rapidly decreased in the Ni layer. A possible cause of the Ni decrease is due to void formation. The average concentration of $\mathrm{Zr}$ at the middle point in the amorphous region was $73 \mathrm{~mol} \%$, as determined by EDX. Since the Ni concentration in the thin third region corresponding to the peak position of $\mathrm{Ni}$ is sufficiently high (approximately $\mathrm{Zr}-85 \mathrm{~mol} \% \mathrm{Ni}$ ), the amor-

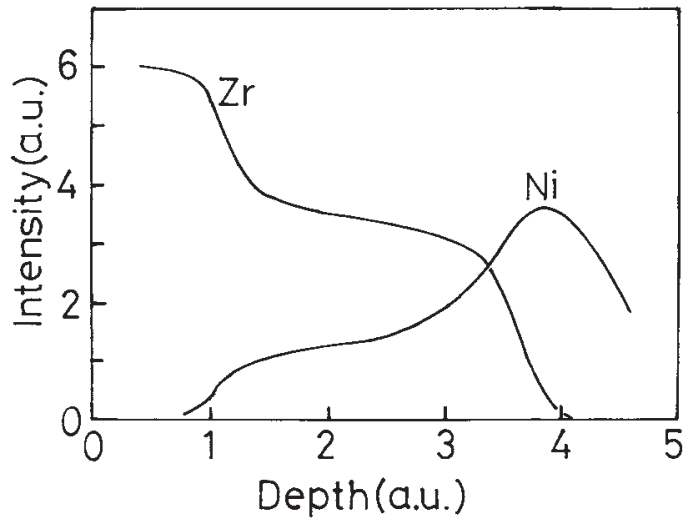

Fig. 4 Depth-composition profiles for $\mathrm{Zr} / \mathrm{Ni}$ bilayer thin film annealed at $623 \mathrm{~K}\left(350^{\circ} \mathrm{C}\right)$ for $3600 \mathrm{~s}(1 \mathrm{~h})$.

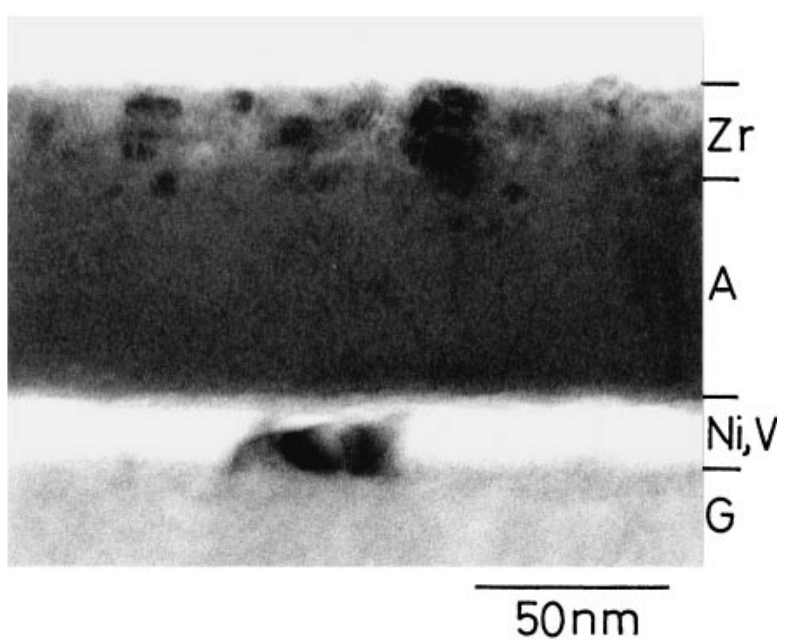

Fig. 5 Cross sectional transmission electron micrograph of $\mathrm{Zr} / \mathrm{Ni}$ bilayer thin film annealed at $623 \mathrm{~K}\left(350^{\circ} \mathrm{C}\right)$ for $7200 \mathrm{~s}(2 \mathrm{~h})$. A, V and $\mathrm{G}$ indicate amorphous, void and glass substrate, respectively.

phous phase was not formed.

The cross-sectional transmission electron micrograph of $\mathrm{Zr} / \mathrm{Ni}$ thin film after annealing at $623 \mathrm{~K}\left(350^{\circ} \mathrm{C}\right)$ for $7200 \mathrm{~s}$ $(2 \mathrm{~h})$ is shown in Fig. 5. The most of the Ni layer contains large voids as a result of vacancy flow and only narrow nickel bridges between the substrate and the amorphous layer were observed.

\section{2 $\mathrm{Ni} / \mathrm{Zr}$ thin film}

The $\mathrm{Ni} / \mathrm{Zr}(/$ glass-substrate $)$ system was examined to clarify the role of vacancies supplied from the $\mathrm{Zr}$ surface. The cross sectional transmission electron micrograph of the specimen annealed at $623 \mathrm{~K}\left(350^{\circ} \mathrm{C}\right)$ for $3600 \mathrm{~s}(1 \mathrm{~h})$ is shown in Fig. 6. Although a large quantity of the amorphous phase observed in the $\mathrm{Zr} / \mathrm{Ni}$ system as shown in Fig. 1, the $\mathrm{Ni} / \mathrm{Zr}$ bilayer film did not show the amorphous phase. In this system, the vacancy is not supplied from the $\mathrm{Zr}$ film side because the film is in contact with the glass substrate. That is, it is necessary that the vacancy is supplied from the free surface of the $\mathrm{Zr}$ layer to form the amorphous phase. The vacancy supplied from the $\mathrm{Zr}$ surface assists the $\mathrm{Ni}$ preferential diffusion towards the $\mathrm{Zr}$. 


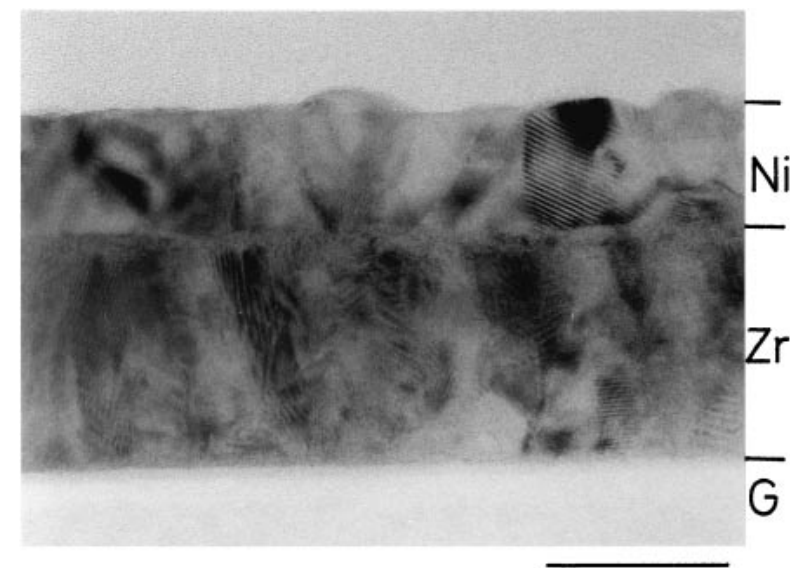

$50 \mathrm{~nm}$

Fig. 6 Cross sectional transmission electron micrograph of $\mathrm{Ni} / \mathrm{Zr}$ bilayer thin film annealed at $623 \mathrm{~K}\left(350^{\circ} \mathrm{C}\right)$ for $3600 \mathrm{~s}(1 \mathrm{~h}) . \mathrm{G}$ indicates glass substrate.

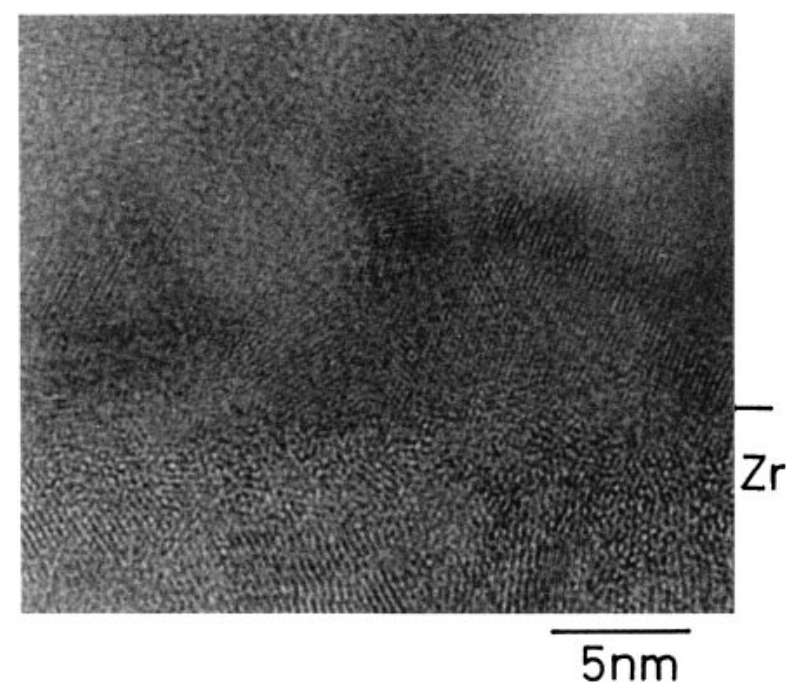

Fig. 7 Lattice image near boundary between the $\mathrm{Ni}$ and the $\mathrm{Zr}$ for $\mathrm{Ni} / \mathrm{Zr}$ bilayer thin film annealed at $623 \mathrm{~K}\left(350^{\circ} \mathrm{C}\right)$ for $3600 \mathrm{~s}(1 \mathrm{~h})$.

However, a small amount of amorphous phase was confirmed near the boundary between $\mathrm{Ni}$ and $\mathrm{Zr}$ layers in a high-resolution transmission electron micrograph. The lattice image near the boundary is shown in Fig. 7. The amorphous phase is observed here and there near the boundary. It is thought that the amorphous formation is due to vacancies and vacancy sauces like dislocations contained in the $\mathrm{Zr}$ thin film.

\section{3 $\mathrm{Zr} /(\mathrm{Ni}-$-oxide $) / \mathrm{Ni}$ film}

$\mathrm{Zr} /(\mathrm{Ni}$-oxide)/Ni(/glass-substrate) film was obtained by surface oxidation of $\mathrm{Ni}$ at room temperature for $3600 \mathrm{~s}(1 \mathrm{~h})$ before sputtering $\mathrm{Zr}$. A cross-sectional transmission electron micrograph of $\mathrm{Zr} /(\mathrm{Ni}$-oxide $) / \mathrm{Ni}$ annealed at $623 \mathrm{~K}\left(350^{\circ} \mathrm{C}\right)$ for $3600 \mathrm{~s}(1 \mathrm{~h})$ is shown in Fig. 8. The amorphous layer grew and the Ni-oxide layer did not interrupt the diffusion of $\mathrm{Ni}$ species into the $\mathrm{Zr}$ layer. However, no voids were observed in the Ni layer.

Depth composition profiles of $\mathrm{Zr} /(\mathrm{Ni}$-oxide $) / \mathrm{Ni}$ film after annealing are shown in Fig. 9. The relative concentration of

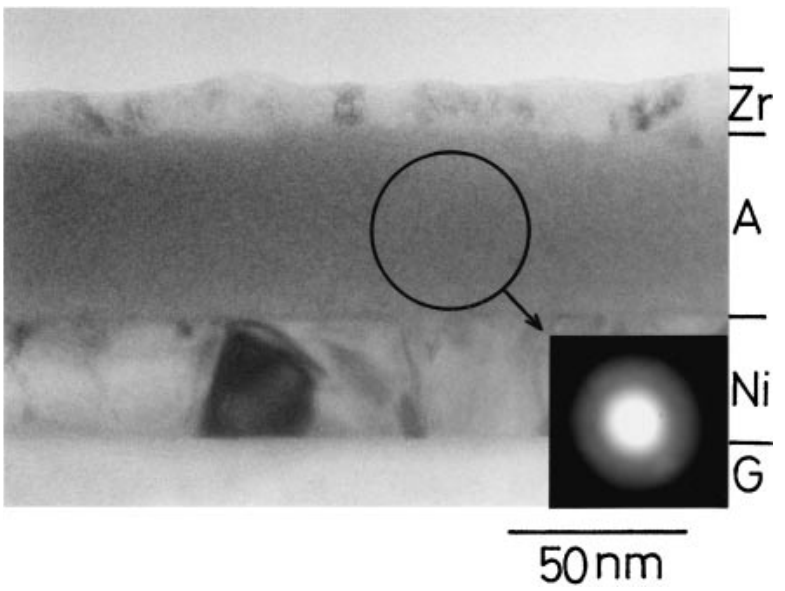

Fig. 8 Cross sectional transmission electron micrograph and electron diffraction pattern of $\mathrm{Zr} /(\mathrm{Ni}$-oxide)/Ni thin film annealed at $623 \mathrm{~K}$ $\left(350^{\circ} \mathrm{C}\right)$ for $3600 \mathrm{~s}(1 \mathrm{~h}) . \mathrm{A}$ and $\mathrm{G}$ indicate amorphous and glass substrate, respectively.

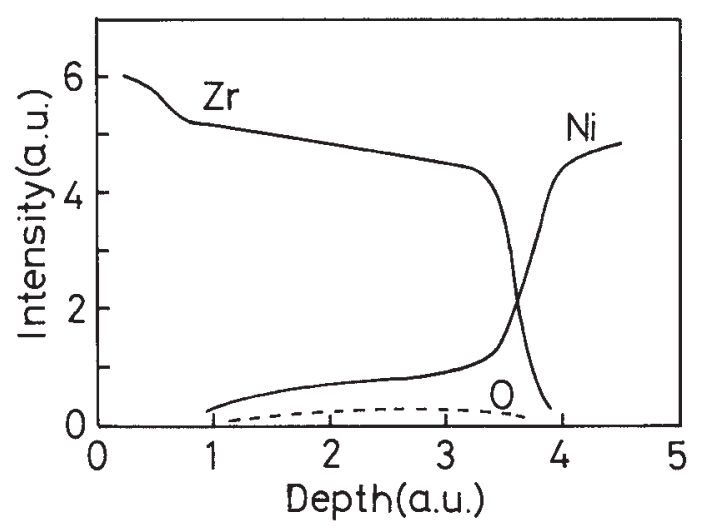

Fig. 9 Depth-composition profiles for $\mathrm{Zr} / \mathrm{Ni}$-oxide/ $\mathrm{Ni}$ thin film annealed at $623 \mathrm{~K}\left(350^{\circ} \mathrm{C}\right)$ for $3600 \mathrm{~s}(1 \mathrm{~h})$.

$\mathrm{Ni}$ in the amorphous layer was low in comparison with that of $\mathrm{Zr} / \mathrm{Ni}$ system shown in Fig. 4. Although the oxygen peak was observed in the as-sputtered specimen, the peak was annihilated after annealing. That is, the Ni oxide decomposed and the oxygen species diffused preferentially into the $\mathrm{Zr}$ layers.

The typical composition of the amorphous layer obtained by EDX was approximately $\mathrm{Zr}-23 \mathrm{~mol} \% \mathrm{Ni}$. This is lower than that of the amorphous phase for annealed $\mathrm{Zr} / \mathrm{Ni}$ thin film. It is therefore thought that the vacancy flow into the $\mathrm{Ni}$ layer is small in comparison with the case of $\mathrm{Zr} / \mathrm{Ni}$ thin film.

\subsection{Effect of Zr-oxide layer}

(Zr-oxide) $/ \mathrm{Zr} / \mathrm{Ni}$ (/glass-substrate) film was obtained by oxidation of the surface of $\mathrm{Zr}$ film at room temperature for $3600 \mathrm{~s}(1 \mathrm{~h})$ before annealing. A cross-sectional transmission electron micrograph of the ( $\mathrm{Zr}$-oxide) $/ \mathrm{Zr} / \mathrm{Ni}$ film annealed at $623 \mathrm{~K}\left(350^{\circ} \mathrm{C}\right)$ for $3600 \mathrm{~s}(1 \mathrm{~h})$ is shown in Fig. 10. Although $\mathrm{Zr}$ and $\mathrm{Ni}$ crystal grains were observed, the amorphous phase was not observed. The supply of vacancy from the $\mathrm{Zr}$ surface was suppressed by the Zr-oxide layer, and the preferential $\mathrm{Ni}$ diffusion into the $\mathrm{Zr}$ layer did not occur. Therefore, the amorphous phase and voids did not grow. 


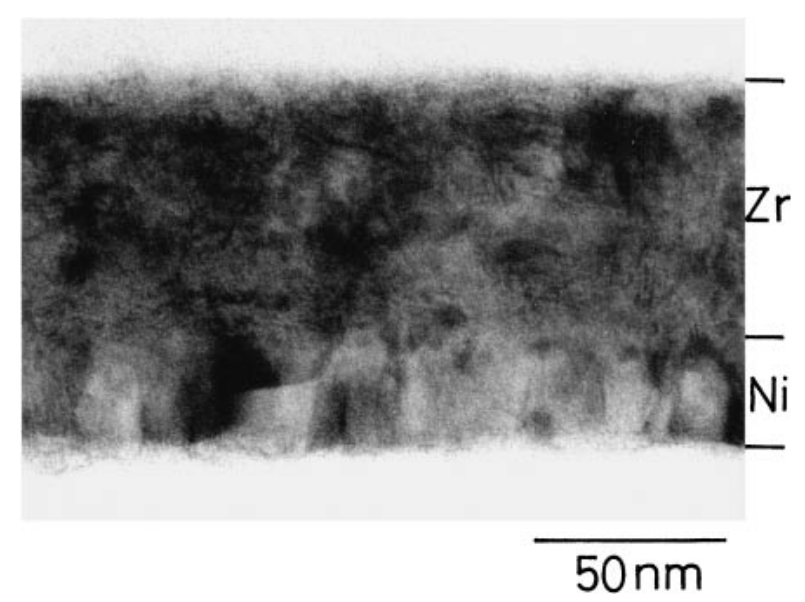

Fig. 10 Cross sectional transmission electron micrograph of (Zr-oxide)/ $\mathrm{Zr} / \mathrm{Ni}$ thin film annealed at $623 \mathrm{~K}\left(350^{\circ} \mathrm{C}\right)$ for $3600 \mathrm{~s}(1 \mathrm{~h})$.

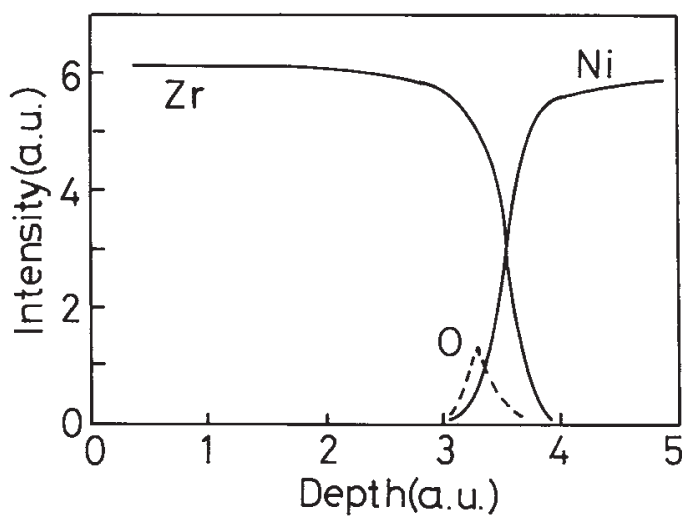

Fig. 11 Depth-composition profiles for $\mathrm{Zr} /(\mathrm{Zr}$-oxide $) / \mathrm{Ni}$ thin film annealed at $623 \mathrm{~K}\left(350^{\circ} \mathrm{C}\right)$ for $3600 \mathrm{~s}(1 \mathrm{~h})$.

The $\mathrm{Zr} /(\mathrm{Zr}$-oxide)/Ni film also did not form the amorphous phase or voids. Migrations of Ni species and vacancies were interrupted by the $\mathrm{Zr}$ oxide layer because the oxide did not decompose. In the depth composition profile, the oxygen peak was detected after annealing, shown in Fig. 11.

No amorphous phase was observed in $\mathrm{Ni} /(\mathrm{Zr}$-oxide $) / \mathrm{Zr}$ thin film in the high-resolution electron micrograph. This is due to the lack of vacancy supply and barrier effect of the oxide.

The sputtering order and the oxide layer had a strong influence on the amorphous and void formations, as mentioned above. To form voids, a large number of vacancies must migrate towards the $\mathrm{Ni}$ underlayer side from the upper $\mathrm{Zr}$ thin film side. Although the sputter films contain many vacancies, this is not sufficient for the formation of large voids as shown in the present results. Lattice defects, such as dislocations and grain boundaries in the $\mathrm{Zr}$ thin films, also contribute as the supply source of vacancies to form the voids. However, these defects also can not make such large voids as shown in the present results. It is therefore thought that the vacancies are supplied from the free surface. When the free surface is clean, the vacancy is able to be supplied from the surface. However, the supply is prevented by the surface oxide layer of the $\mathrm{Zr}$ thin film.

On the other hand, many vacancies migrate towards the $\mathrm{Ni}$ underlayer and form voids. This phenomenon shows that vacancies aid the migration of $\mathrm{Ni}$ species in the amorphous phase. That is, the preferential diffusion of $\mathrm{Ni}$ species into the $\mathrm{Zr}$ layer is promoted by vacancy-like defects in the amorphous layer.

\section{Conclusion}

The effects of oxide layer and sputtering order of $\mathrm{Zr}-\mathrm{Ni}$ thin films on the amorphous phase and void formations were studied. Although the amorphous and voids are observed in $\mathrm{Zr} / \mathrm{Ni}$ thin films, these were not observed in (Zr-oxide)/Zr/ $\mathrm{Ni}$ and $\mathrm{Ni} / \mathrm{Zr}$ thin films. This indicates that the nickel species migrate preferentially with the assistance of vacancy into the amorphous layer and vacancies are supplied from the zirconium free-surface.

\section{REFERENCES}

1) Pol Duwez, R. H. Willens and W. Klement, Jr.: J. Appl. Phys. 31 (1960) 1136-1140.

2) Y. Limoge and A. Barbu: Phys. Rev. B 30 (1984) 2212-2214.

3) R. M. Idrus and P. J. Grundy: J. Phys. D: Appl. Phys. 27 (1994) 129133.

4) R. B. Schwarz and W. L. Johnson: Phys. Rev. Lett. 51 (1983) 414-416.

5) M. Raible, S. G. Mayr, S. J. Linz, M. Moske, P. Hunggi and K. Samwer: Europhys. Lett. 50 (2000) 61-63.

6) S. G. Mayr, M. Moske and K. Samwer: Mater. Sci. Forum 343-346, pt. 1, (2000) 221.

7) K. Brinkmann, K. Chenmann and H. Teichler: NIC Symposium, Proc., NIC Series 9 (2002) 233-235.

8) O. Hayama, H. M. Kimura, N. Nishiyama and A. Inoue: Mater. Trans. 45 (2004) 861-865.

9) M. Kitada and K. Yamamoto: J. Magn. Magn. Mater. 147 (1995) 213217.

10) M. Kitada and N. Shimizu: J. Mateials Sci. Lett. 10 (1991) 437-438.

11) M. Kitada, N. Shimizu and H. Tanabe: J. Mater. Sci. 6 (1991) 835-838.

12) W. S. Lai and B. X. Liu: J. Mater. Res. 13 (1998) 1712-1717.

13) M. Atzmon and F. Spaepen: Materials Research Society Symposia proceedings, (Pittsburg, 1987) pp. 55-56.

14) N. Karpe, J. Bottiger, J. P. Krog, J. S. Coyners and R. E. Somekh: Philos. Mag. A 75 (1997) 461-465. 